\title{
APRENDIZAGEM BASEADA EM PROBLEMA: INTERDISCIPLINARIDADE ENTRE ACADÊMICOS DA ADMINISTRAÇÃO E DE CIÊNCIAS CONTÁBEIS
}

\author{
LIÉGE PIRES DO ROSÁRIO LAU ${ }^{1}$, SANDRA BELLOLI DE VARGAS ${ }^{2}$.
}

\begin{abstract}
1 Mestre em Ciências Sociais Aplicadas. Especialista em Administração e Estratégia Empresarial. Psicóloga. Professora do Curso de Administração da Faculdade Dom Bosco de Porto Alegre/RS, liegeprl@gmail.com.

${ }^{2}$ Doutoranda no Programa de Pós-graduação em Ciências Contábeis da Universidade do Vale do Rio dos Sinos (UNISINOS). Mestre em Ciências Contábeis pela Universidade do Vale do Rio dos Sinos (UNISINOS). sandrabelloli@terra.com.br
\end{abstract}

\section{RESUMO}

O objetivo deste artigo foi relatar as experiências de aplicações de metodologias ativas de forma interdisciplinar entre acadêmicos da Administração e de Ciências Contábeis de uma instituição privada de ensino superior. A pesquisa caracteriza-se como descritiva com abordagem qualitativa realizada através de um estudo de caso. A metodologia de ensino utilizada foi Aprendizagem baseada em problema (PBL- Problem Based Learning). Os principais resultados indicam que a interdisciplinaridade propicia o desenvolvimento de competências valorizadas no mercado de trabalho como, por exemplo, capacidade analítica, mediação de conflitos nos grupos, além da argumentação.

Palavras-chave: Aprendizagem Baseada em Problema; Aprendizagem Ativa; Interdisciplinaridade.

\section{PROBLEM-BASED LEARNING: INTERDISCIPLINARITY AMONG MANAGEMENT AND ACCOUNTANCY ACADEMICS}

\begin{abstract}
The purpose of this article is to report the experiences of applications of active methodologies in an interdisciplinary way among academics of Administration and Accounting of a private institution of higher education. The research is characterized as descriptive with a qualitative approach carried out through a case study. The teaching methodology used was problem-based learning. The main results indicate that indisciplinarity promotes the development of skills valued in the labor market, such as, for example, analytical capacity, conflict mediation in groups, in addition to argumentation.
\end{abstract}

Keywords: Problem Based Learning; Active learning; Interdisciplinarity. 


\section{INTRODUÇÃO}

O contexto da educação superior no Brasil passa por um processo de mudanças deixando de ser um direito ou serviço público prestado para se tornar um negócio mediante as operações em que grandes instituições educacionais nacionais ou internacionais se associam para aumentarem sua participação no mercado (SGUISSARDI, 2015). Há que se questionar esse contexto, argumenta Sguissardi (2015), que força um movimento de democratização ou de massificação da educação superior. Contudo, não há uma resposta conclusiva para tal questão, para o autor, o que existe uma mercantilização da educação superior.

Para Schwartzman (2017), a educação superior passa por um momento de expansão no Brasil decorrente da demanda crescente do mercado de trabalho por profissionais melhor qualificados, isso somado à possibilidade de prestígio, reconhecimento social e pela possibilidade de melhores rendas associadas ao grau de instrução. Por esse motivo, nos últimos anos, as investigações sobre cultura, mente, cérebro, cognição e desenvolvimento indicaram novos insights para a aprendizagem que trouxeram novas concepções para esse processo e impulsionaram a disseminação de novas práticas pedagógicas (LIMA, 2016).

No século $\mathrm{XX}$, o modelo educacional se caracterizou por um conjunto de disciplinas administradas de maneira fragmentada, o que não contribui para uma aprendizagem integrada do conteúdo. Atualmente, o processo de ensino-aprendizagem tem o propósito de formar o aluno na sua integralidade, de desenvolver competências socioemocionais e técnicas. Logo, é necessário encontrar formas de apresentar os temas de forma diferente da exposição tradicional, por módulos não integrados.

Guedes, Andrade e Nicolini (2015) destacam o papel da internet como propulsor de novas maneiras de aprender. O principal ponto, na opinião dos autores, é treinar os discentes a buscar novos conhecimentos durante a vida profissional. Encontrar formas de apresentar o conteúdo programático diferente da exposição tradicional, dar aos alunos o sentido dos temas abordados em aula para suas vidas profissional e pessoal de forma que eleve ao máximo a aprendizagem são reflexões importantes para o ser professor. 
Diante dessa perspectiva, o objetivo deste artigo foi relatar as experiências de aplicações de metodologias ativas de forma interdisciplinar entre acadêmicos da Administração uma instituição privada de ensino superior com a aplicação do recurso de aprendizagem baseada em problema (ABP). Conforme argumentam Guedes, Andrade e Nicolini (2015), preparar os discentes para atender às expectativas do mercado em relação à habilidade de resolução de problemas, trabalhar em equipe, atuar de maneira ética e atentar para as questões de cidadania, requer da IES melhorias no processoensino aprendizagem e uma alternativa é a utilização das metodologias ativas.

Este artigo está organizado em cinco seções, além dessa introdução. A segunda seção apresenta o referencial teórico. A terceira seção trata da metodologia. Na quarta, tem-se os resultados e a discussão e a última seção apresenta as considerações finais do estudo e recomendações para estudos futuros.

\section{APRENDIZAGEM BASEADA EM PROBLEMA}

É inegável que as mudanças ocorridas nos negócios impactam na vida dos discentes e das instituições de ensino, principalmente, as de ensino superior. As IES precisam formar profissionais que atuem de maneira integrada e concreta na sociedade (BERBEL, 2011). Como ferramenta de apoio às IES, na missão de formar tais profissionais, utilizam-se as metodologias ativas de aprendizagem. Conforme argumenta Valente, Almeida e Geraldini (2017), as metodologias se caracterizam pela utilização de práticas pedagógicas que colocam o aluno na posição de protagonista do seu aprendizado. Dentre as metodologias, a aprendizagem baseada em problema vem sendo utilizada nas áreas de Administração e Ciências Contábeis, pois parte de situações-problemas e, muitas vezes, vivenciadas no cenário empresarial.

A Aprendizagem baseada em problema (ABP) emergiu como proposta pedagógica no final dos anos de 1960, especialmente na área da saúde, por diversas instituições de ensino superior (COSTA, 2011). A ABP propicia um maior envolvimento dos discentes no processo de aprendizagem, estimula a pesquisa, permitindo que o discente assuma o controle na busca do conhecimento na tentativa de reduzir a resistência à aprendizagem (SIQUEIRA et al., 2009). 
Segundo Berbel (2011), a ABP começou a ser utilizada no Brasil pela área de medicina, contudo, já se expandiu às demais. Essa metodologia contribui para a formação à medida que os discentes se responsabilizam pela busca do conhecimento. Siqueira et al. (2009) reforça que um dos principais aspectos de sua contribuição no processo de aprendizagem pode ser identificado a partir da capacidade de aquisição de incrementos nos graus de autonomia na aprendizagem.

Destacam-se como principais perspectivas da ABP, de acordo com Siqueira et al. (2009), a saber: (a) aprendizagem significativa - etapa a qual o discente associa o novo conteúdo a conteúdos já aprendidos; (b) indissociabilidade entre a teoria e a prática - relação que se estabelece a partir da resolução das situações problemas que requerem o conhecimento teórico para serem solucionadas; (c) o respeito à autonomia do discentes - estimula-se através dessa metodologia que o discente assuma a responsabilidade por sua aprendizagem; (d) trabalho em pequenos grupos - utilização de grupos de discentes e um tutor para que se desenvolva a habilidade de cooperação na busca da solução para o problema; (e) educação permanente - considerado um elemento base na $\mathrm{ABP}$, refere-se a entender que o tempo da graduação não é suficiente para que o discente adquira tantos conhecimentos que a utilização de situações problemas pode propiciar; e (f) avaliação formativa - possibilita uma avaliação dos envolvidos que auxilia à formação de discentes e docentes.

Apresenta-se, a seguir, alguns estudos realizados nas áreas de Administração e Ciências Contábeis que apoiarão a análise dos resultados dessa pesquisa.

\section{ESTUDOS ASSEMELHADOS}

\subsection{Estudos assemelhados na Administração}

Sugahara, Jannuzzi e Sousa (2012) discorrem sobre a possibilidade de as metodologias ativas, especificamente a $\mathrm{ABP}$, orientarem a questão pedagógica da interdisciplinaridade no curso de Administração. O principal resultado identificado pelos autores foi de que os alunos ingressantes do curso de Administração participaram do Exame Nacional de Desempenho dos Estudantes (ENADE) e apresentaram melhor 
desempenho em conteúdo de formação geral comparados aos alunos ingressantes em Administração de outras instituições de ensino.

Borochovicius e Tortella (2014) avaliaram a aplicação da ABP no curso de Administração de uma universidade do interior de São Paulo nas disciplinas de matemática financeira, administração financeira 1 e administração financeira 2. A análise da proposta pedagógica do curso e o plano de ensino das disciplinas permitiu identificar se as situações problemas, que são formuladas e apresentadas aos discentes pelos docentes, não sejam facilmente relacionadas aos tópicos desses documentos. Foi observado que as situações-problemas foram trabalhadas de forma interdisciplinar. As situações-problemas não são revisadas com muita frequência dado o pouco tempo dos professores e que elas passam por um grupo de professores para análise antes da aplicação. Por fim, os autores concluíram, com base nos resultados dos relatórios finais apresentados, que o empenho dos discentes propiciou resultados superiores e medianos cujo reflexo foi percebido na nota da prova.

A pesquisa de Souza e Verdelli (2014) avaliou a utilização da aprendizagem baseada em problema nas disciplinas do curso de Administração. Os resultados foram obtidos por meio da aplicação de um questionário aos discentes. Do total de discentes, $25 \%$ consideraram a atividade como grande facilitadora do aprendizado, $23 \%$ avaliaram como pouco facilitadora no processo de aprendizagem e $52 \%$ dos discentes consideraram que a ABP facilita moderadamente o aprendizado. Ainda, os resultados apontaram que, em relação ao trabalho em equipe, os discentes trocaram mais informações e se sentiram mais confiantes. Em relação as habilidades individuais, não foram percebidas como a ABP contribuiu.

O estudo de Guedes, Andrade e Nicolini et al. (2015) verificou o impacto do uso da Aprendizagem baseada em problemas na percepção dos estudantes e dos professores em uma instituição de ensino superior. Os professores não mencionaram dificuldades na aplicação do método e manifestaram surpresa diante do empenho e do desempenho dos discentes. Uma dificuldade observada pelos professores foi de que os discentes apresentaram dificuldades em correlacionar o conteúdo aprendido com o que é instrumento para resolver a situação-problema. A falta de engajamento e o comprometimento de alguns discentes com o grupo ficou evidente, demonstrando que não sabem dividir tarefas e trabalhar em grupo. Os discentes que participaram do 
trabalho afirmam que existe diferenças entre a aula tradicional e o uso desse método (ABP). Eles comentam que essa experiência propiciou uma visão diferente de situações da vida real, deixando-as mais fáceis de serem compreendidas. Contudo, os discentes relatam que tiveram muitas dificuldades para iniciar a tarefa sem a orientação do professor.

\subsection{Estudos assemelhados em Ciências Contábeis}

A pesquisa de Siqueira et al. (2009) procurou coletar e analisar as opiniões de um grupo de alunos de Ciências Contábeis expostos à metodologia $\mathrm{ABP}$ com intuito de detectar uma sinalização sobre a oportunidade de se aplicá-la ou não. Os principais resultados indicaram que os alunos percebem que é possível aplicar a PBL na contabilidade com ajustes, principalmente em disciplinas acompanhadas de teoria como, por exemplo, a disciplina de contabilidade gerencial, embora, alguns alunos mencionarem que a metodologia é pouco conhecida. Cabe destacar que a principal vantagem percebida mencionada se refere ao estímulo à pesquisa por parte dos alunos, entretanto, a principal desvantagem citada é de que a ABP possibilita uma cobertura incompleta do conteúdo, complementam os autores.

Pinheiro, Sarrico e Santiago (2011) analisaram o papel que a ABP tem no desenvolvimento das competências pessoais dos discentes, melhoram-se tais competências ao comparar com alunos que não foram expostos a metodologia e como ela reflete no perfil dos alunos. Os achados da pesquisa apontam que foi possível identificar que a PBL contribuiu para gestão do tempo, planificação de tarefas, análise crítica, capacidade de síntese, criatividade, fundamentação de decisões, iniciativa, dinamismo e metodologia de trabalho. De forma menos acentuada, foi percebido uma melhora na capacidade de comunicação, oral e escrita, organização pessoal e definição de objetivos. Ao analisar a percepção dos diplomados, os autores destacam que as opiniões são divididas, alguns identificam e avaliam positivamente a PBL e outros afirmam que podem contribuir para a melhoria das competências já mencionadas.

O estudo de Oliveira et al. (2013) propôs a analisar se há relação das variáveis idade, gênero e estilo de aprendizagem na percepção de estudante de contabilidade sobre o emprego de estratégias lúdicas. Os resultados da pesquisa indicam que a maioria dos estudantes de Contabilidade possui como característica o aprendizado por meio da 
prática. Não existe relação entre a percepção destes alunos sobre estratégias lúdicas e gênero, bem como não foi identificada relação entre a percepção deles sobre estratégias lúdicas e idade. Entretanto, a maioria dos estudantes concordam com aspectos positivos das estratégias lúdicas no ensino da Contabilidade, mesmo não tendo experiência com essa estratégia de aprendizagem, concluem os autores.

A pesquisa de Martins, Espejo e Frezatti (2015) relata a operacionalização da ABP na disciplina de Contabilidade gerencial. Os achados indicam que a PBL permitiu que os discentes desenvolvessem habilidades tais como: pensamento crítico, capacidade de identificar, analisar e resolver problemas complexos e reais, permitindo uma forte interdisciplinaridade. Durante a aplicação da ABP, foi constatada a necessidade do aluno de ter aulas expositivas, com conteúdo apresentado pelo professor, de forma expositiva. Contudo, ficou evidenciada a valorização por parte dos alunos do papel desenvolvido pelos tutores na contribuição no processo de busca do conhecimento e desenvolvimento das habilidades requeridas.

Diferentemente das pesquisas apresentadas anteriormente, Oliveira et al. (2015), investigaram a percepção do docente a respeito do uso da ABP no curso de Ciências Contábeis. Em relação ao conhecimento referente sobre a ABP, os docentes afirmaram que adquiram mais conhecimento por conta própria ao longo dos anos. Os docentes entrevistados informaram que utilizam a metodologia nas aulas da graduação e pósgraduação. Um ponto destacado pelos docentes é de que a aplicação da $\mathrm{ABP}$ na disciplina que contempla, por exemplo, as normas contábeis a aplicação da metodologia não foi bem aceita pelos discentes, pois o assunto não permitia muitas discussões, complementam os autores.

\section{METODOLOGIA}

O objetivo deste trabalho o caracteriza como uma pesquisa qualitativa, tendo como procedimento de coleta de dados o estudo de caso. De acordo com Yin (2015, p.17), o estudo de caso pode ser definido como "uma investigação empírica que verifica um fenômeno contemporâneo (o 'caso') em profundidade e em seu contexto de mundo real", especificamente quando os limites entre o fenômeno e o contexto não estão claramente definidos. 
A aplicação da metodologia aprendizagem baseada em equipe ocorreu no segundo semestre de 2017. A professora do curso de Administração e a professora do curso de Ciências Contábeis se propuseram a utilizar a metodologia aprendizagem baseada em equipe de forma interdisciplinar em duas turmas durante o semestre. A seleção das turmas foi feita por conveniências, pois ambas eram ministradas na mesma noite, fato que oportunizava a realização do trabalho em conjunto.

A situação problemática apresentada aos alunos foi discutida entre as professoras com partir do plano de ensino da disciplina de Gestão contemporânea de pessoas que elegeram o tópico cujo problema foi elaborado. A metodologia aprendizagem baseada em problema foi escolhida, porque as professoras pretendiam com a aplicação dessa técnica, desenvolver a capacidade de pesquisa, trabalho em equipe, capacidade de síntese e comprometimento com o grupo nas turmas escolhidas.

As professoras apresentaram uma situação problemática da atividade empresarial, para 25 discentes que participaram da atividade. Após a apresentação do caso, as professoras propuseram aos alunos que estudassem o conteúdo por meio de um trabalho em conjunto, entre os colegas da disciplina de Gestão contemporânea de pessoas e da disciplina de Análise de custos. Os alunos das duas turmas concordaram.

Foi destacado, para os alunos, a importância da experiência de vivenciarem uma parceria entre acadêmicos de diferentes cursos; de como trabalhar/estudar em uma equipe interdisciplinar com um mesmo objetivo/resultados; e, de pensarem como gestores/empreendedores com visão integrada do processo. $\mathrm{Na}$ aula seguinte, as turmas foram reunidas e divididas em grupos de cinco alunos de ambos os cursos para assistirem o documentário "A dura rotina de quem trabalha em frigoríficos", de 55 minutos, que ilustra a situação problemática. Os discentes puderam fazer anotações sobre o documentário.

Para a turma de Gestão contemporânea de pessoas foi proposta uma questão para resolver a situação problemática: como melhorar as condições de trabalho de forma que promova a qualidade de vida do trabalhador e atenda os objetivos do negócio? Portanto, foi solicitado que apresentassem possíveis soluções para os problemas enfrentados pelos trabalhadores dos frigoríficos. As soluções deveriam estar alinhadas com o conteúdo já estudado na disciplina e deveriam ser incluídas outras práticas ainda não estudadas, ou seja, os alunos precisariam pesquisar sobre o tema. 
Os acadêmicos da disciplina de Análise de custos, juntamente com a professora, retornaram para sua respectiva sala de aula e foram orientados a refletirem sobre o documentário e informados que receberiam as propostas elaboradas pelos alunos de Gestão contemporânea de pessoas para que providenciassem uma análise do impacto no custo que as alternativas sugeridas trariam a empresa. A professora da disciplina disponibilizou às discentes demonstrações financeiras de empresas que atuam no segmento em questão para uma análise prévia.

A professora de Gestão contemporânea de pessoas, atuando como mediadora, facilitava o trabalho dos alunos, explicando como preencher o formulário (objetivo, meta, causas, indicadores, ações) e registrando no quadro a solução de cada grupo. Esta atividade gerou uma lista das possíveis soluções e cada grupo selecionava e avisava a professora qual a solução escolhida a ser desenvolvida, dessa maneira, cada grupo se ocupou de soluções diferentes. Ou seja, os alunos em grupo, discutiram os elementos do problema e criaram uma lista de aspectos mais importantes e das possíveis soluções. Eles pesquisaram em livros, materiais disponíveis (internet, artigos) e encontraram soluções para o problema. As possíveis soluções de cada grupo foram enviadas aos grupos de Ciências contábeis para análise e quantificação do impacto monetário para a empresa.

Os discentes de Ciências contábeis, no laboratório de informática, iniciaram a leitura e análise das possíveis soluções encontradas por cada grupo de discentes da disciplina de gestão de pessoas. O tempo previsto para essa atividade foi 1 hora e 50 minutos. Os discentes utilizaram a internet para pesquisar sobre questões trabalhistas, equipamento de proteção individual, normas de segurança no trabalho especificamente a NR36 que trata da segurança e saúde no trabalho em empresas de abate e processamento de carnes e derivados, preços dos equipamentos etc. Para cada alternativa, sugerida foi realizado a estimativa dos custos.

$\mathrm{Na}$ segunda parte da aula, as turmas foram reunidas em sala de aula para que os discentes de Ciências contábeis apresentassem as estimativas de custos e possíveis questões relacionadas à legislação trabalhista ou à NR36. A apresentação começou tímida, com a mediação e incentivo das professoras, contudo, à medida que as alternativas foram apresentadas (e seus impactos no custo da empresa), os discentes de Gestão contemporânea de pessoas começaram a fazer perguntas aos discentes de 
Ciências contábeis sobre as alternativas propostas por eles. Nesse momento, as professoras não fizeram intervenções. Após esse debate, a professora de Gestão contemporânea de pessoas perguntou aos discentes qual conjunto de alternativas poderia ser implantado mediante a estima de custos, questões trabalhistas e de segurança do trabalho. Os alunos discutiram e elegeram as melhores sugestões para a situaçãoproblema.

Após a realização dessas etapas, foi aplicado o questionário de avaliação utilizando a escala Likert de cinco pontos, cujo cinco representa a maior concordância e um a menor. Os resultados desse questionário geraram os resultados apresentados na próxima seção. As professoras foram entrevistadas pelas pesquisadoras após a conclusão da aplicação da metodologia.

\section{RESULTADOS}

Nesta seção, apresentamos os resultados obtidos e suas correspondentes análises. Os resultados dessa pesquisa refletem a percepção e as atitudes durante a aplicação da metodologia dos discentes e professoras envolvidas na aplicação da metodologia.

\subsection{Resultados do Curso de Administração}

O Gráfico 1 apresenta o resultado da percepção dos discentes de administração sobre o quanto aprenderam com o uso da metodologia APB. 
Gráfico 1: Percepção do discente em relação à aprendizagem

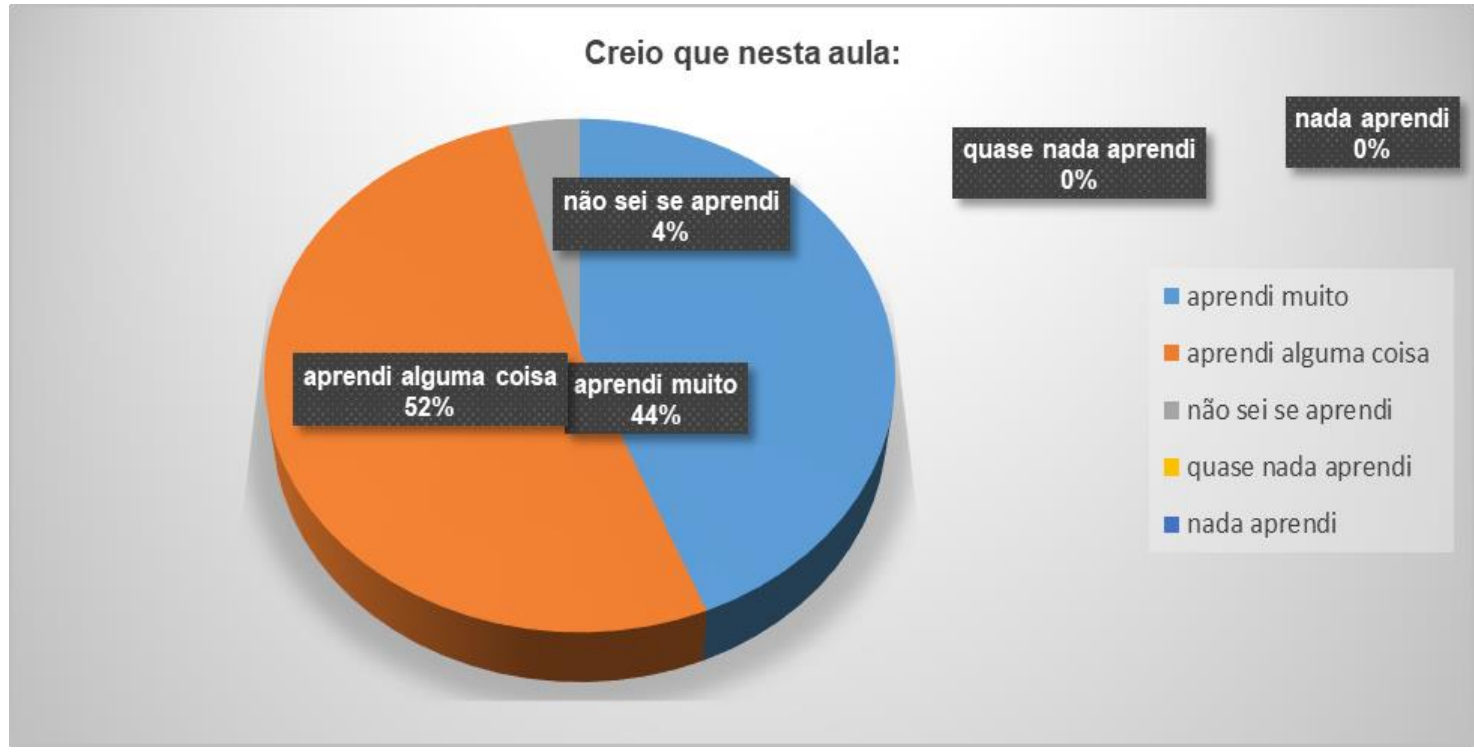

Fonte: dados da pesquisa.

Os resultados apontam que $96 \%$ dos discentes respondem que aprenderam alguma coisa ou aprenderam muito. Esse resultado difere-se do apresentado por Souza e Verdelli (2014) no qual 52\% dos discentes consideram a metodologia como uma facilitadora moderada. Em elação ao grau de satisfação e/ou insatisfação da aplicação do método, $40 \%$ dos alunos se declaram muito satisfeitos, $36 \%$ bastantes satisfeitos, $16 \%$ mais ou menos satisfeitos; $4 \%$ pouco satisfeitos; enquanto $4 \%$ indiferentes.

No Gráfico 2, em comparação com a aula expositiva, 44\% dos alunos disseram ser muito melhor com a ABP; $32 \%$ relataram ser melhor; $20 \%$ é igual a aula tradicional e $4 \%$ é pior. 
Gráfico 2: Comparação com a aula tradicional

A atividade que foi desenvolvida, em comparação com uma aula tradicional expositiva foi:

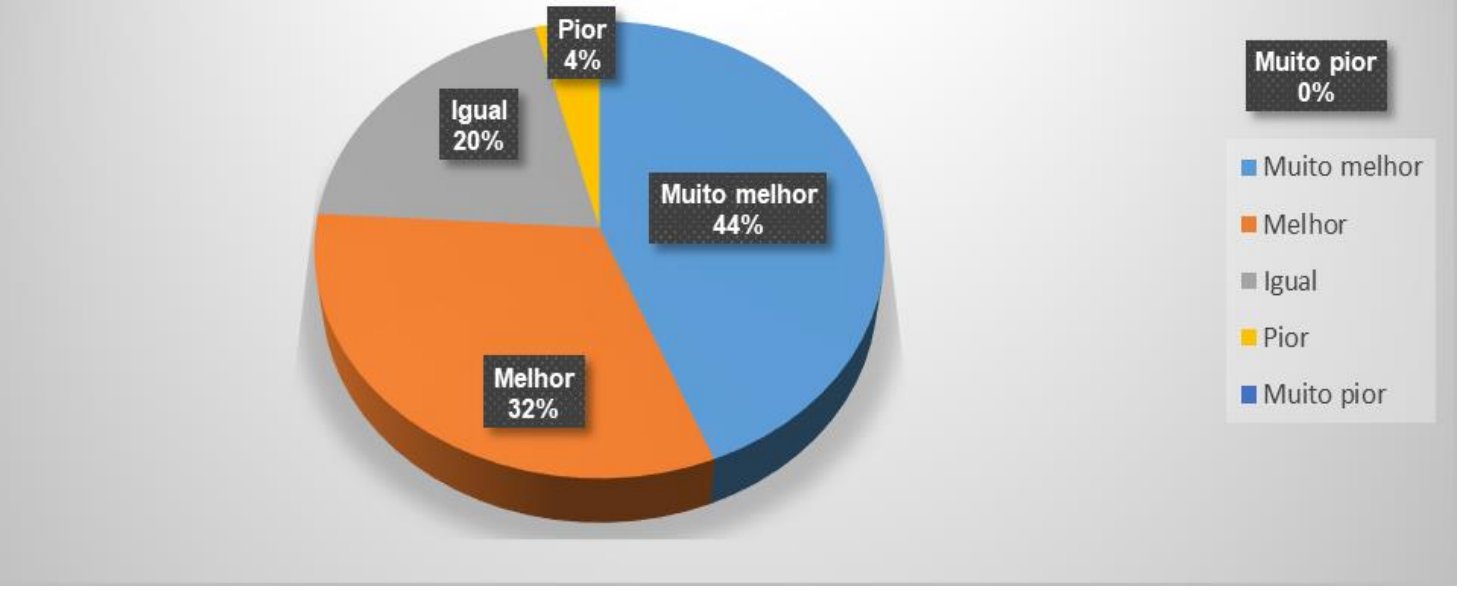

Fonte: dados da pesquisa.

Esse resultado confirma a pesquisa feita anteriormente por Guedes, Andrade e Nicolini et al. (2015), ou seja, os alunos percebem a diferença entre as metodologias de ensino utilizadas e consideram que o uso de metodologias ativas é melhor do que a aula tradicional. Esse dado também é confirmado com a próxima questão que compara o conteúdo aprendido com uso da ABP e a aula expositiva, pois $64 \%$ dos discentes relataram ser efetivo; $24 \%$ disseram ser muito mais efetivo; $8 \%$ igual; e, $4 \%$, pior que a aula expositiva.

Em relação as facilidades da utilização da metodologia, os discentes de Administração, responderam: "trabalhar em equipe", " debates, reflexões, informações de custos", "absorção do conteúdo", "a facilidade de ter visto as necessidades, apontar onde poderiam ser mudadas e mensurar o valor", "entendimento do conteúdo", "a visão do tema por diferentes áreas", "aprender de forma prática", "a compreensão da matéria". As principais dificuldades apontadas foram: "dificuldade de escolher tarefa", "divergência de opiniões", "falta de conhecimentos específicos", "nenhuma, "acho de pensar em como poderíamos fazer algo para melhorar este ramo", "falta de clareza", "não como carne", "a busca pelo tema a ser abordado", "buscar informações de conteúdo", "escolher um único problema'. Ainda, em relação às dificuldades, 44 \% dos discentes apontaram buscar os conteúdos necessários; $24 \%$ disseram não haver dificuldade; $16 \%$ relataram que foi pouco tempo para buscar os conteúdos e desenvolver 
a atividade; outros $16 \%$ mencionaram a mediação de conflitos entre os participantes do grupo.

A avaliação da atividade pontuou nota máxima $(5,0)$ por $50 \%$ dos alunos, enquanto $32 \%$ atribuíram nota 4,$0 ; 13 \%$ nota 3,$0 ;$ e, $4 \%$ nota 0 , conforme demonstrado no Gráfico 3.

Gráfico 3: Nota para a avaliação da atividade

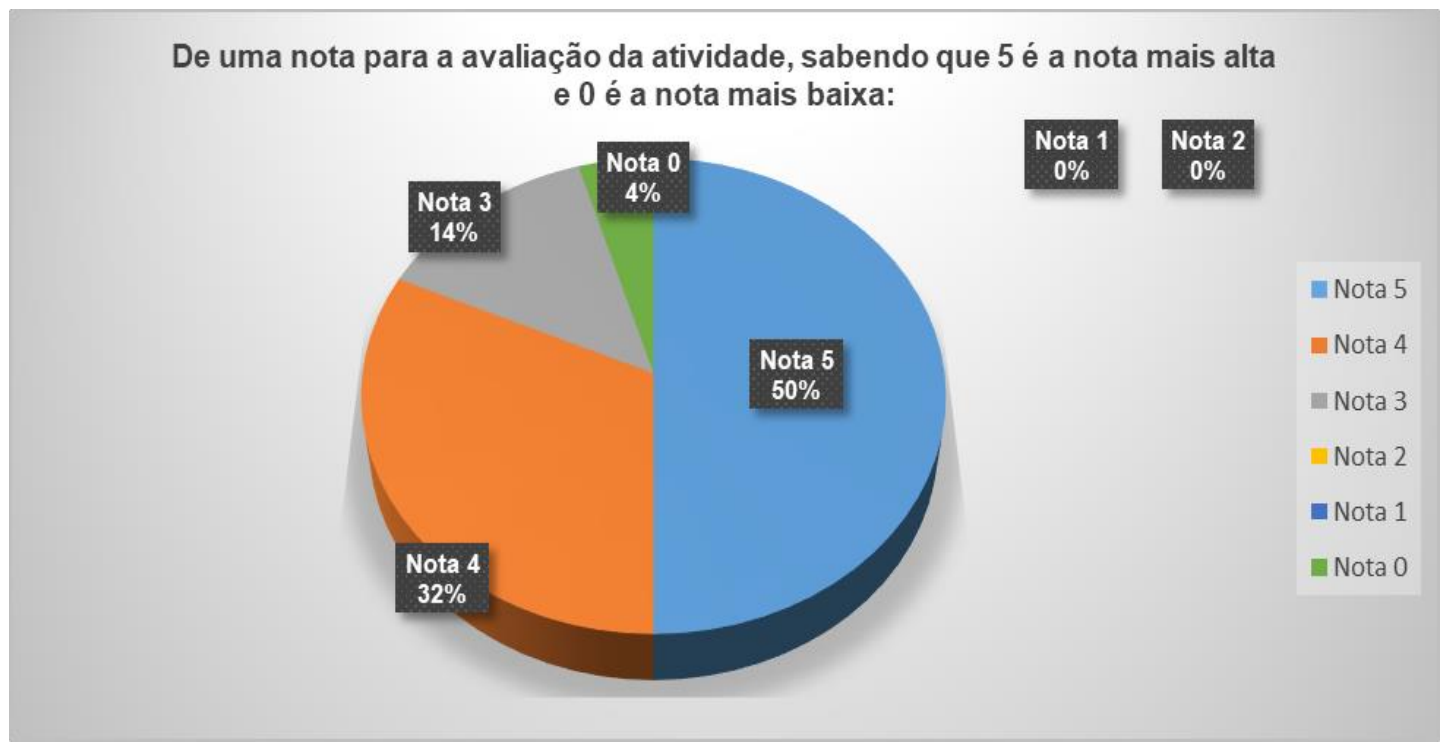

Fonte: dados da pesquisa.

Ao serem questionados se ficaram satisfeitos com este método, os discentes de Administração mencionaram: "aula diferente”, "aprendizado extremamente eficaz", "foi interessante", "porque tivemos a parte prática e depois nos foi concretizado como poderia ser realizado", "colocarmos em prática", "tive a visão e oportunidade de aprender sobre o assunto por diferentes áreas", "foge do método tradicional e o conteúdo quando posto em prática fica mais fácil de compreender e aprender”. Em relação a possíveis frustrações, somente foi mencionado que "conteúdo desinteressante".

Foi perguntado aos alunos se gostariam de repetir a experiência de utilizar a ABP em outras disciplinas e $95 \%$ deles responderam que sim. Os discentes, por fim, relataram que: "gostei da forma da aula juntando alunos de contábeis com administração e outros cursos", "atividade foi muito produtiva, os professores estão de parabéns pela iniciativa que além de integrar diversos cursos diferentes nos proporcionou uma visão diferente do assunto", "foi uma ótima experiência, podendo pensar como uma empresa", 
"muito boa experiência, sempre sendo orientado pelo professor", "de início achei que não entenderia a situação, mas depois dos resultados apresentados percebe que este tipo de atividade é muito produtivo e compreensível."

\subsection{Resultados do Curso de Ciências Contábeis}

O Gráfico 4 apresenta o resultado da percepção dos discentes de Ciências contábeis sobre o quanto aprenderam com o uso da metodologia APB.

Gráfico 4: Percepção do discente em relação à aprendizagem

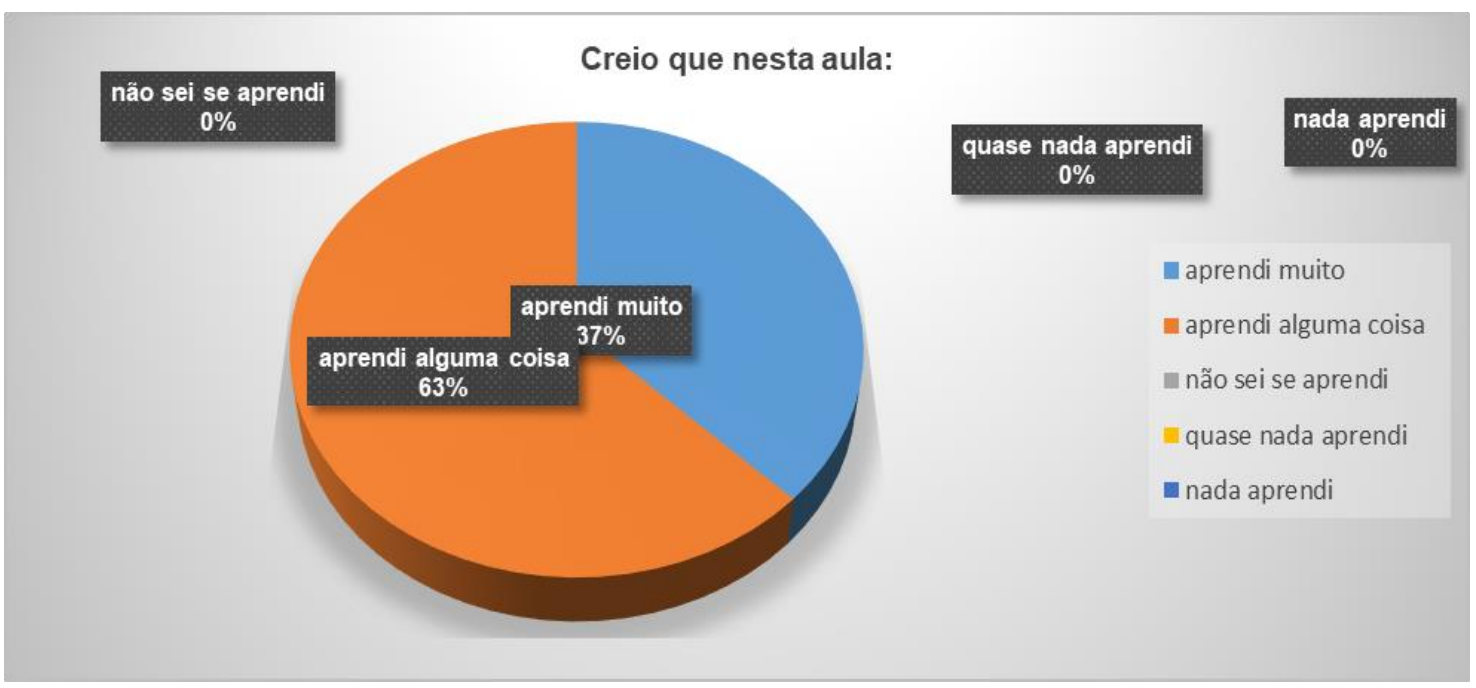

Fonte: dados da pesquisa.

Os resultados apontaram que $100 \%$ dos discentes responderam que aprenderam alguma coisa ou aprenderam muito. Esse fato pode ser atribuído ao fato de que a maioria dos estudantes de Contabilidade possui como característica o aprendizado por meio da prática (OLIVEIAA et al., 2013).

No Gráfico 5, em comparação com a aula expositiva, 25\% dos alunos disseram ser muito melhor a ABP; $50 \%$ relataram ser melhor e $25 \%$ é igual a aula tradicional. 
Gráfico 5: Comparação com a aula tradicional

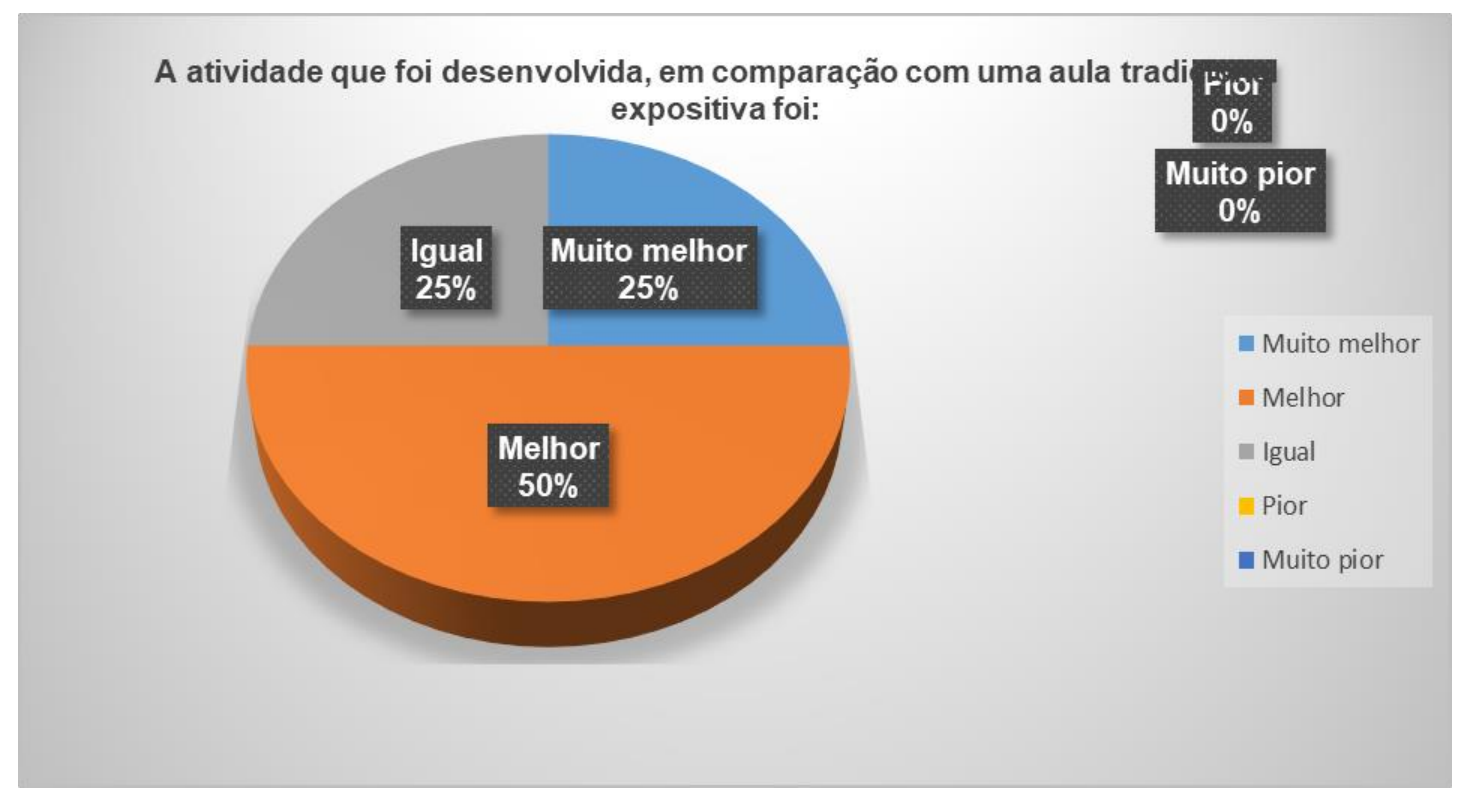

Fonte: dados da pesquisa.

Esse resultado confirma a pesquisa de Oliveira et al. (2013), evidenciando a preferência dos discentes de Ciências contábeis pelas atividades práticas. Esse dado também é confirmado com a próxima questão que compara o conteúdo aprendido com uso da $\mathrm{ABP}$ e a aula expositiva, pois $62 \%$ dos discentes relataram ser efetivo; $25 \%$ disseram ser muito mais efetivo e $13 \%$ consideraram igual a aula expositiva.

Em relação as facilidades da utilização da metodologia, os discentes de Ciências Contábeis responderam "assunto interessante", "facilidade de compreender" e "interação com a turma". As principais dificuldades apontadas foram: "busca de conteúdos", "falta de dados mais precisos", "busca de dados sobre funcionários", "pouco tempo", "nada para ilustrar". Ainda, em relação às dificuldades, 62\% dos discentes apontaram buscar os conteúdos necessários e 38\% mencionaram pouco tempo para buscar conteúdo e desenvolver a atividade.

A avaliação da atividade pontuou nota máxima $(5,0)$ por $50 \%$ dos alunos, enquanto $32 \%$ atribuíram nota 4,$0 ; 13 \%$ nota 3,0 ; e, $4 \%$ nota 0 , conforme demonstrado no Gráfico 6. 
Gráfico 6: Nota para a avaliação da atividade

De uma nota para a avaliação da atividade, sabendo que 5 é a nota mais alta e 0 é a nota mais baixa:

Nota 1 Nota 2

$0 \%$

$0 \%$

Nota 3 Nota 5

Nota 0

$0 \%$

Nota 5

$25 \%$

$25 \%$

Nota 4

Nota 3

Nota 2

- Nota 1

Nota 4

Nota 0

$50 \%$

Fonte: dados da pesquisa.

Ao serem questionados se ficaram satisfeitos com este método, os discentes de Ciências Contábeis mencionaram: "trabalhamos em grupo", "entramos em um assunto diferente do comum", "agregou conhecimento", “debatemos e aprendemos dinamicamente", "integração das turmas", "ter na uma aula mais dinâmica é fácil de compreensão e não deixando o aluno cansado", "por ser mais dinâmica e menos tradicional , trabalhando em grupo foi diferente e teve participações de outros colegas", "foi diferente e com bastante interação" e "foi bastante diferente". Em relação a possíveis frustrações, somente foi mencionado que "falta de tempo". Foi perguntado aos alunos se gostariam de repetir a experiência de utilizar a ABP em outras disciplinas e $100 \%$ deles responderam que sim."

\subsection{Percepção das Professoras}

A aplicação da Aprendizagem baseada em problemas demonstrou a importância de o método ser visto como um meio e não um fim no processo de ensinoaprendizagem. Por isso, a necessidade de planejamento, a compreensão em qual contexto este instrumento se insere para que se obtenha o efeito desejado. Ficou claro o papel das professoras como facilitadoras que incentivam o aprendizado do 
acadêmico com o assunto proposto, trazendo conhecimento prévio, esclarecendo as dúvidas e dividindo comentários.

Coube às facilitadoras a responsabilidade de gerenciamento da aula, escolher o material adequado e de boa qualidade, enfim, que mantenham o interesse do estudante, contendo um roteiro com o objetivo, causas, indicadores, referências sobre o conteúdo, bem como incentivar a autonomia, o compartilhamento de informações, colaboração, respeito as diferenças, aspectos estes exigidos no mercado de trabalho. Lidar com as diferentes reações dos alunos, alguns mais tímidos e/ou resistentes a didáticas de aula diferentes, outros mais comunicativos e abertos a novas práticas de aprendizagem, fazem parte do desafio do professor. Não somente o aluno, mas o professor deve se dispor a ensinar e aprender com formatos diferentes das aulas clássicas-lineares.

No início da atividade, os discentes de Ciências Contábeis se mostraram desconfiados, não entenderam por que precisavam assistir ao documentário juntamente com a turma de Administração. Ao conhecer exatamente o que se esperava deles, a tensão começou a se dissipar; contudo, a questão do tempo esteve presente durante a execução da atividade. "Mas foi possível verificar a satisfação dos discentes foi evidente durante a realização da atividade", afirma a professora.

No momento final, em que as turmas foram reunidas, complementa a professora, os discentes ficaram tímidos e à medida que foram apresentando a análise e as estimativas de custos, o debate iniciou. Os acadêmicos se sentiram mais à vontade para expor o conhecimento adquirido até aquele estágio do curso. De volta a sala de aula, relata a professora, os alunos relataram o orgulho em demonstrarem seus conhecimentos sobre o tema. Em relação as dificuldades por parte do docente, a professora não identificou nenhuma.

\section{CONCLUSÕES}

O objetivo deste artigo foi relatar uma experiência interdisciplinar entre o curso de Administração e Ciências Contábeis da aplicação da Aprendizagem baseada em problema de uma instituição privada de ensino superior. As disciplinas participantes do projeto foram Gestão Contemporânea de Pessoas e Análise de Custos.

O que se percebe, a partir dos relatos das experiências com a adoção da ABP, contribui para que os discentes associem os conceitos teóricos e à prática empresarial. A 
partir da apresentação da situação problemática, percebeu-se que os discentes buscaram informações para propor as alternativas para resolução do problema, as estimativas de custos e, posteriormente, após as argumentações chegaram à conclusão da melhor possibilidade.

Conforme os resultados obtidos por meio da aplicação do questionário de avaliação, se conclui que foi percebido pelos alunos, que as metodologias ativas propiciam alinhamento entre a teoria estudada em sala e a prática no mercado de trabalho. No caso do curso de Ciências Contábeis, os alunos em sua maioria trabalham durante o dia e propiciar aulas com uso de outras metodologias, além da tradicional aula expositiva, contribui para a fixação do conteúdo. A participação dos alunos e a possibilidade de conflitos no grande grupo oportuniza para o aprimoramento da capacidade de argumentação, exposição e confrontação das ideias.

Com base nesses resultados, infere-se que a utilização da metodologia Aprendizagem baseada em problemas pode contribuir para a melhoria do processo de aprendizagem e o resultado dessa aplicação é constatado pelos discentes e docentes. Diferentemente de outras pesquisas, não houve resistência na utilização das metodologias.

$\mathrm{Na}$ percepção das professoras, os alunos das duas disciplinas participaram ativamente das atividades, portanto, foi possível identificar o desenvolvimento de competências, tais como capacidade analítica e de síntese, capacidade de buscar conhecimento de maneira autônoma e comprometimento com o grupo.

Com base nesses resultados, infere-se que a utilização da metodologia Aprendizagem baseada em problemas pode contribuir para a melhoria do processo de aprendizagem e o resultado dessa aplicação é constatado pelos discentes e docentes. Diferentemente de outras pesquisas, não houve resistência na utilização das metodologias.

A pesquisa possui limitações como, por exemplo, a metodologia foi aplicada em apenas duas turmas, ampliar o projeto para inserção de turmas de outros cursos, pode apresentar resultado diferente. Recomenda-se a aplicação para turmas de acadêmicos de disciplinas em diferentes semestres, a fim de perceber se há diversas formas de percepção entre alunos em fase inicial do curso e fase final do curso. 
As metodologias ativas apresentam uma oportunidade para desenvolvimento de pesquisas futuras. Sugere-se o aprimoramento da situação problema e inserção de alternativas para busca de informações, com objetivo de mitigar a questão do tempo na execução da atividade. A inclusão um grupo focal com docentes e discentes para debate da situação problema, com objetivo de mitigar quaisquer dúvidas em relação a atividade realizada.

\section{REFERÊNCIAS}

BERBEL, Neusi Aparecida Navas. As metodologias ativas e a promoção da autonomia de estudantes. Semina: Ciências Sociais e Humanas, v. 32, n. 1, p. 25-40, 2011. Disponível em: http://www.uel.br/revistas/uel/index.php/seminasoc/article/view/10326

BOROCHOVICIUS, Eli; TORTELLA, Jussara Cristina Barboza. Aprendizagem Baseada em Problemas: um método de ensino-aprendizagem e suas práticas educativas. Ensaio: Avaliação e Políticas Públicas em Educação, v. 22, n. 83, p. 263294, 2014. Disponível em: https://www.scielo.br/scielo.php?pid=S0104$\underline{40362014000200002 \& \text { script }=\text { sci } \text { arttext }}$

COSTA, Valéria CI. Aprendizagem baseada em problemas (PBL). Revista Távola Online, n. 5-3, 2011.

GUEDES, Karine de Lima; ANDRADE, Rui Otavio Bernardes; NICOLINI, Alexandre Mendes. A avaliação de estudantes e professores de administração sobre a experiência com a aprendizagem baseada em problemas. Administração: Ensino e Pesquisa, v. 16, n. $1, \quad$ p. 71-100, 2015. Disponível em: https://www.redalyc.org/pdf/5335/533556755005.pdf

LIMA, Valéria Vernaschi. Espiral construtivista: uma metodologia ativa de ensinoaprendizagem. Interface-Comunicação, Saúde, Educação, v. 21, p. 421-434, 2016. Disponível em: https://www.scielosp.org/article/icse/2017.v21n61/421-434/

MARTINS, Daiana Bragueto; ESPEJO, Márcia Maria dos Santos Bortolocci; FREZATTI, Fábio. Problem-Based Learning no ensino de contabilidade gerencial: relato de uma experiência brasileira. Revista de Educação e Pesquisa em Contabilidade (REPeC), v. 9, n. 4, 2015. Disponível em: http://www.repec.org.br/repec/article/view/1340

OLIVEIRA, André Junior; RAFFAELLI, Susana Cipriano Dias; COLAUTO, Romualdo Douglas; CASA NOVA, Silvia Pereira. Estilos de aprendizagem e estratégias ludopedagógicas: percepções no ensino da contabilidade. Advances in Scientific and Applied Accounting, v. 6, n. 2, p. 236-262, 2013. Disponível em: http://asaa.anpcont.org.br/index.php/asaa/article/view/117 
OLIVEIRA, Elisabeth Vendramini; LIMA, João Paulo Resende; FARIAS, Raíssa Silveira; ARAÚJO, Adriana Maria Procópio. O Que Pensam os Professores a Respeito do Problem Based Learning como Estratégia de Ensino na Contabilidade? Revista de Graduação USP, v. 3, n. 2, p. 45-53, 2018. Disponível em: https://www.revistas.usp.br/gradmais/article/view/147910

PINHEIRO, Margarida M.; SARRICO, Cláudia S.; SANTIAGO, Rui A. Competências de auto-desenvolvimento metodologias PBL num curso de contabilidade. 2011. Disponível em: http://recil.grupolusofona.pt/handle/10437/1476

SCHWARTZMAN, Simon. Perspectivas para a educação superior no Brasil. Desafios da nação: artigos de apoio. Brasília: Ipea, 2017. Disponível em: https://www.redalyc.org/pdf/766/76652988005.pdf

SIQUEIRA, José Ricardo Maia. SIQUEIRA-BATISTA, Rodrigo. MORCH, Rafael Borges. SIQUEIRA-BATISTA, Romulo. Aprendizagem baseada em problemas: o que os médicos podem ensinar aos contadores. Contabilidade Vista \& Revista, v. 20, n. 3, p. 101-125, 2009. Disponível em: https://www.redalyc.org/pdf/1970/197014573005.pdf

SGUISSARDI, Valdemar. Educação superior no Brasil. Democratização ou massificação mercantil? Educação \& Sociedade, v. 36, n. 133, p. 867-889, 2015. Disponível em: $\quad$ https://www.scielo.br/scielo.php?pid=S0101$73302015000400867 \&$ script $=$ sci_arttext\&tlng=pt

SOUZA, Nilana Rodrigues; VERDINELLI, Miguel Angel. Aprendizagem ativa em administração: Um estudo da aprendizagem baseada em problemas (PBL) na graduação. Revista Pretexto, v. 15, n. NE, p. 29-47, 2014. Disponível em: http://www.fumec.br/revistas/pretexto/article/view/1496

SUGAHARA, Cibele Roberta; JANNUZZI, Celeste Aída Sirotheau Corrêa; DE SOUSA, José Eduardo. O ensino-aprendizagem baseado em problema e estudo de caso num curso presencial de Administração-Brasil. Revista Ibero-americana de Educación, $\quad$ n. $60 / 1, \quad 1912 . \quad$ Disponível em: https://rieoei.org/historico/expe/4872Sugahara.pdf

VALENTE, José Armando; DE ALMEIDA, Maria Elizabeth Bianconcini; GERALDINI, Alexandra Fogli Serpa. Metodologias ativas: das concepções às práticas em distintos níveis de ensino. Revista Diálogo Educacional, v. 17, n. 52, p. 455-478, 2017. Disponível em: https://www.redalyc.org/pdf/1891/189154955008.pdf

YIN, R. K. Estudo de caso planejamento e métodos. 4. ed. Porto Alegre: Bookman, 2015. 